\title{
Epidural pneumorrhachis consequent to Hamman syndrome
}

Prasad Krishnan, Sayan Das ${ }^{1}$, Chandramouli Bhattacharyya ${ }^{2}$

Department of Neurosurgery, National Neurosciences Centre, Departments of ${ }^{1}$ Radiodiagnosis and ${ }^{2}$ Internal Medicine, Peerless Hospital, Kolkata, West Bengal, India

A 30-year-old male patient presented with sudden onset shortness of breath, chest pain, hypotension, swelling of the upper part of the body, and severe tingling sensation of all four limbs after a bout of coughing. There was no history of trauma. On examination, he was found to have subcutaneous emphysema on the front of chest and neck. Computed tomography (CT) scan of the chest revealed pneumomediastinum with subcutaneous emphysema. There was no pneumothorax. Air was present in the spinal canal in the epidural space at the cervical and dorsal spinal levels. Parasagittal and coronal cuts revealed air in the intervertebral foramina as well [Figure 1]. The patient was treated with multiple subcutaneous incisions, symptomatic medications, and with time, the tingling and dysesthesias resolved.

Spontaneous mediastinal and subcutaneous emphysemas (eponymously called Hamman syndrome) are due to rupture of alveoli, following rise in intrabronchial pressure usually after a bout of coughing, shouting, or vomiting. ${ }^{[1]}$ It has also been described after labor. ${ }^{[1]}$

Address for correspondence:

Dr. Prasad Krishnan, Department of Neurosurgery, National Neurosciences Centre, Peerless Hospital Campus, $2^{\text {nd }}$ Floor, 360 Panchasayar, Kolkata - 700 094, West Bengal, India.

E-mail: prasad.krishnan@rediffmail.com

\begin{tabular}{|l|l|}
\hline \multicolumn{2}{|c|}{ Access this article online } \\
\hline Quick Response Code: & Website: \\
\hline & www.ruralneuropractice.com \\
\cline { 2 - 3 } & \\
\hline & DOI: \\
\hline
\end{tabular}

The air tends to dissect along the fascial planes of the mediastinum into the subcutaneous space. Rarely, it may enter into the spinal canal through the intervertebral foramina (as in this case) after dissecting along the path of the exiting spinal roots. The thin peripheral location of the air in the canal as seen on axial imaging confirmed that it is epidural in nature (also called external pneumorrhachis). ${ }^{[2,3]}$ In other situations - after surgery, penetrating injury, infection by gas forming organisms, or lumbar puncture - the air is intradural (internal pneumorrhachis) ${ }^{[2,3]}$ and tends to occupy more central location. Further epidural pneumorrhachis usually collects in the posterior epidural space due to the presence of loose connective tissue that provides lesser resistance than the vascular network present anteriorly. ${ }^{[2]}$

CT scans are the investigation of choice to diagnose pneumorrhachis. ${ }^{[3]}$ There are no guidelines for its treatment, and although the majority of epidural pneumorrhachis is self-limiting, intervention must be considered if there are severe neurological deficits. ${ }^{[2]}$

\section{Financial support and sponsorship \\ Nil. \\ Conflicts of interest \\ There are no conflicts of interest.}

This is an open access article distributed under the terms of the Creative Commons Attribution-NonCommercial-ShareAlike 3.0 License, which allows others to remix, tweak, and build upon the work non-commercially, as long as the author is credited and the new creations are licensed under the identical terms.

For reprints contact: reprints@medknow.com

How to cite this article: Krishnan P, Das S, Bhattacharyya C. Epidural pneumorrhachis consequent to Hamman syndrome. J Neurosci Rural Pract 2017;8:118-9. 


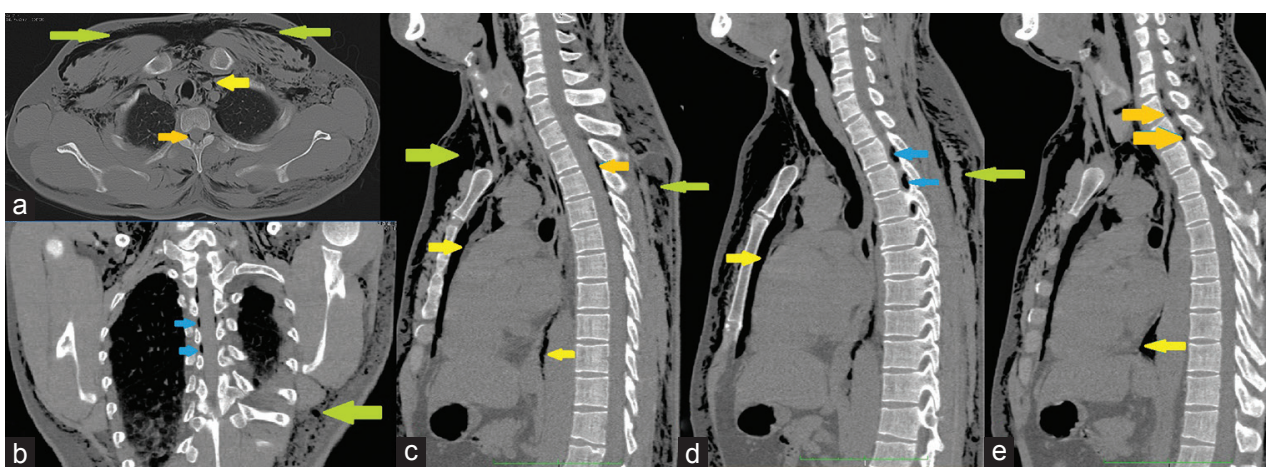

Figure 1: (a) Axial, (b) coronal, and (c-e) sagittal and parasagittal computed tomography scan cuts showing subcutaneous emphysema in the front and back of thorax and anterior aspect of neck (green arrows), air in superior, anterior, and posterior mediastinum (yellow arrows), thin peripherally located epidural intraspinal air (orange arrows), and air in intervertebral foramina (blue arrows) which is the route of ingress into the spinal canal

\section{References}

1. Weissberg D, Weissberg D. Spontaneous mediastinal emphysema. Eur J Cardiothorac Surg 2004;26:885-8
2. Oertel MF, Korinth MC, Reinges MH, Krings T, Terbeck S, Gilsbach JM. Pathogenesis, diagnosis and management of pneumorrhachis. Eur Spine J 2006;15 Suppl 5:636-43.

3. Singh J, Kharosekar H, Velho V. Post-operative intradural tension pneumorrhachis. Neurol India 2013;61:664-5. 